Ágora Rev. Cient. 2019; 06(02):e6

\title{
Rol de los interferones tipo I y tipo III: Una revisión de conceptos
}

\section{Role of type I and type III interferons: A review of concepts}

Obert Marín-Sánchez ${ }^{1,2,4}$, Dan Vivas-Ruiz ${ }^{3}$, Miguel Neira ${ }^{3,4}$, Gustavo A. Sandoval ${ }^{3,4}$, Olegario MarínMachuca $^{5}$, Ana Juliet Rodriguez-Landauro ${ }^{6}$, Ruy D. Chacón ${ }^{7,8}$

\section{RESUMEN}

Los interferones (IFN), inicialmente denominados como "mediadores solubles que interfieren con la infección celular por el virus de la gripe A", son familias de proteínas secretadas que regulan la inmunidad innata y adquirida tras la activación de receptores de reconocimiento de patrones (PRR). Los IFN tienen un impacto en los procesos de proliferación, diferenciación y muerte celular. Los IFN, dependiendo de las características moleculares del gen que lo codifica y los receptores diana, se dividen en tres familias: IFN tipo I (IFN $\alpha$, IFN $\beta$, IFN $\omega$, IFN $\tau$, IFN $\varepsilon$ ), tipo II (IFN $\gamma$ ) y tipo III (IFN $\lambda 1$, IFN $\lambda 2 / 3$, IFN $\lambda 4$ ). En este contexto, la presente revisión brinda los principales conceptos sobre los interferones tipo I y tipo III dado que ambos comparten la misma cascada de señalización; aunque, el mecanismo de acción de IFN tipo III, sea aún poco conocido, estos pueden ser empleados como agentes biológicos en comparación los IFN tipo I.

Palabras clave: interferón tipo I, interferón tipo III, inmunidad innata, inmunidad adquirida, regulación inmunológica.

\begin{abstract}
The interferons (IFN), initially referred to as "soluble mediators that interfere with cell infection by influenza A virus", are families of secreted proteins that regulate innate and acquired immunity after activation of pattern recognition receptors (PRR). The IFN have an impact on the processes of proliferation, differentiation and cell death. The IFN, depending on the molecular characteristics of the gene that encodes it and the target receptors, are divided into three families: type I IFN (IFN $\alpha$, IFN $\beta$, IFN $\omega$, IFN $\tau$, IFN $\varepsilon$ ), type II (IFN $\gamma$ ) and type III (IFN $\lambda 1$, IFN $\lambda 2 / 3$, IFN $\lambda 4$ ). In this context, the present article briefly provides important concepts on type I and type III since both share the same signaling cascade; although the mechanism of action of type III IFN, is still little known, these can be used as biological agents compared to type I IFN.
\end{abstract}

Palabras clave: type I interferon, type III interferon, innate immunity, acquired immunity, immune regulation

\footnotetext{
${ }^{1}$ Departamento de Microbiología Médica. Facultad de Medicina. Universidad Nacional Mayor de San Marcos. Lima - Perú. ${ }^{2}$ Instituto de Medicina Tropical "Daniel Alcides Carrión”. Universidad Nacional Mayor de San Marcos. Lima - Perú ${ }^{3}$ Instituto de Ciencias Biológicas “Antonio Raimondi”. Universidad Nacional Mayor de San Marcos. Lima - Perú ${ }^{4}$ Grupo de Investigación en Bioinformática y Biología Estructural. Universidad Nacional Mayor de San Marcos. Lima - Perú ${ }^{5}$ Departamento Académico de Ciencias Alimentarias. Facultad de Oceanografía, Pesquería, Ciencias Alimentarias y Acuicultura. Universidad Nacional Federico Villarreal. Lima - Perú.

${ }^{6}$ Facultad de Odontología. Universidad Nacional Mayor de San Marcos. Lima - Perú.

${ }^{7}$ Departamento de Patologia. Faculdade de Medicina Veterinária e Zootecnia. Universidade de São Paulo - Brasil

${ }^{8}$ Programa de Pós-Graduação Interunidades em Biotecnologia. Instituto de Ciências Biomédicas. Universidade de São Paulo Brasil.
}

\section{INTRODUCCIÓN}

A lo largo de la evolución, los sistemas fisiológicos en el ser humano y en los animales, han ido adaptándose a las diversas circunstancias (nuevas fuentes alimenticias y niveles de oxígeno) y los nuevos entornos en el que se desarrollaban (radiación solar, frio, temperatura). Cada uno de estos factores, bióticos o abióticos, marcaban una pauta para el desarrollo de una adaptación progresiva que terminaba en la adquisición de una novedad evolutiva. Sin embargo, ningún otro sistema se ha visto más continuamente presionado a desarrollar nuevas adaptaciones que el sistema 
inmunológico. Puesto que la ingesta de un nuevo alimento o el asentarse en un nuevo ambiente involucraba el contacto con nuevos agentes extraños (patogénicos o no), lo cual significaba un nuevo reto para el sistema inmunológico [1].

Inicialmente se tenía por concepto que el sistema inmunológico distinguía lo "propio" de lo "extraño". Esta connotación cambió a medida que se fueron conociendo mejor las funciones del sistema inmológico, tales como, administrar y regular una serie de procesos biológicos que orquestan los mecanismos de defensa. Actualmente, los vastos estudios han determinado que en realidad el sistema inmunológico distingue lo "inocuo" de lo "nocivo". Para desarrollar esta prominente labor, el sistema inmunológico comprende una serie de componentes tales como: órganos, tejidos, células y moléculas, que al mismo tiempo pueden realizar actividades independientes para regular la inmunidad innata y la inmunidad adaptativa [2]. De esta manera, el éxito del funcionamiento del sistema inmunológico a lo largo de la evolución se debe a una acertada participación de las moléculas encargadas de la comunicación celular entre sus componentes denominadas citoquinas. Estas inician la activación o la inhibición de procesos biológicos que desencadenan mecanismos de defensa para la erradicación de patógenos y agentes extraños o infecciosos [1].

Las citoquinas (llamadas también citocinas) son proteínas secretadas por células que actúan como un sistema de señales entre las células, permitiendo una respuesta inmune integrada, regulando importantes funciones biológicas, tales como proliferación, activación, sobrevida, muerte, diferenciación celular; entre otras [3]. Un grupo particular de citoquinas son los interferones (IFN), inicialmente descritas por Isaacs y Lindenmann en 1957 [4,5] por su capacidad de interferir con la replicación del virus de la gripe A. Posteriormente los IFN fueron descritos en importantes procesos, como la proliferación, diferenciación y muerte celular. Los IFN son un grupo de proteínas que se clasifican en familias, tales como los IFN tipo I (IFN $\alpha$, IFN $\beta$, entre otros), los IFN tipo II (IFN $\gamma$ ) y los IFN tipo III (IFN $\lambda 1$, IFN $\lambda 2$, IFN $\lambda 3$, e IFN $\lambda 4$ ) [3].

En el presente artículo de revisión se describe las principales características de los IFN tipo I y los IFN tipo III en la regulación de la respuesta inmunológica.

\section{LA FAMILIA DE INTERFERONES TIPO I}

\section{Expresión, receptor y mecanismos de señalización}

Los IFN tipo I ( $\alpha$ y $\beta$ ) son producidos en respuesta a la infección viral y se producen en una variedad de células, principalmente en las células dendríticas plasmocitoides. La inducción de la transcripción de estos genes (IFN $\alpha$ e IFN $\beta$ ) es un evento central en la inmunidad innata. Los IFN tipo I ejercen sus efectos mediante la activación de la vía de señalización JAK/STAT (Janus Kinase/Signal Transducers and Activators of Transcription) [6].

Actualmente, en los seres humanos, los IFN tipo I forman una gran familia heterogénea de citoquinas helicoidales, que incluye a $\operatorname{los}$ IFN $\alpha$ (14 genes en el cromosoma 9 que codifican más de 22 productos), IFN $\beta$, IFN $\varepsilon$ y los subtipos de IFN $\omega$. Estas citoquinas son, en su mayoría proteínas no glicosiladas con homologías desde el $30 \%$ hasta el $85 \%$ dentro de las especies [7].

Los IFN tipo I se unen al complejo receptor IFNAR (receptor de IFN tipo I) que se expresan ubicuamente. Luego de esta unión, se produce la activación de los factores Janus kinasa 1 (JAK1) y Tirosina kinasa 2 (Tyk2) que conducen a la fosforilación de las proteínas transductoras de señal y activadoras de transcripción (STAT1 y STAT2), a través de su dominio de homología Src2 (SH2). El dominio SH2 está asociado con la proteína IRF9 (factor 9 de regulación de interferón) que forma el complejo ISGF3 (factor 3 del gen estimulado por IFN) el cual, posteriormente, se transloca al núcleo y se une a elementos de respuesta sensibles a interferón (ISREs) para iniciar la transcripción de múltiples genes inducidos por interferón (ISGs). El factor IRF7 (factor 7 de regulación de interferón), que tiene un elemento ISRE en su promotor se activa por el sistema JAK-STAT. Entonces, el factor IRF3, (factor 3 de regulación de interferón), que se encuentra en su forma latente en el citoplasma se activa por fosforilación inmediatamente después de la entrada del virus a la célula. Juntos, IRF7 e IRF3, activan la transcripción de IFN $\alpha$ e IFN $\beta$, amplifican la señal a través de un mecanismo de retroalimentación positiva. Este mecanismo tiene como objetivo asegurar la transcripción de genes implicados en la respuesta celular antiviral. Además, IRF2 (factor 2 de regulación de interferón) inhibe el factor de transcripción ISGF3 de IFN $\alpha$ e IFN $\beta$ por competencia a los elementos ISRE presentes en los promotores de genes inducidos por IFN $\alpha$ e IFN $\beta$, disminuyendo así su expresión (Figura 2).

Por lo tanto, el control fino del sistema de señalización del interferón es esencial para la regulación de la inmunidad innata y adaptativa, ya que las células $\mathrm{T} \mathrm{CD}^{+}$(Linfocitos $\mathrm{T}$ 
cooperadores), células $\mathrm{T} \mathrm{CD}^{+}$(linfocitos $\mathrm{T}$ citotóxicos), células dendríticas y macrófagos pueden ser activados por factores quimiotácticos, moléculas de complejo mayor de histocompatibilidad (MHC), citoquinas y otros factores $[6,8]$.

\section{Actividades biológicas y terapéuticas}

Los IFN tipo I ejercen diferentes actividades biológicas, tales como anti-virales, antiproliferativas, pro-apoptóticas y efectos inmunorreguladores. Los IFN tipo I interfieren con la infección por virus ARN y ADN. En los seres humanos, IFN 22 fue probado inicialmente para tratar la hepatitis $\mathrm{C}$ crónica, que resultó en una respuesta virológica sostenida y curativa en hasta el $20 \%$ de los pacientes. El tratamiento actual de hepatitis $\mathrm{C}$ crónica es realizado mediante un IFNa2 PEG-ilado (conjugado covalente formado por la unión de interferón al polímero polietilenglicol) más un inhibidor de nucleósido (ribavirina), el cual cura hasta el $60 \%$ de los pacientes, pero la respuesta al tratamiento depende del genotipo viral y los factores genéticos [7]. La primera aprobación de la FDA (Food and Drug Administration, USA) para los IFN tipo I fue para tratar la tricoleucemia con IFNa2a/ $\alpha 2 b$. En la actualidad, el IFN $\alpha 2 b$ pegilado se utiliza por sus propiedades anti-proliferativas y su actividad proapoptótica, así como un adyuvante de la respuesta inmune en pacientes con melanoma en etapa III. [9].

La actividad inmunorreguladora del IFN $\beta$ es aprovechada para el tratamiento de esclerosis múltiple (RR-MS), una enfermedad autoinmune e inflamatoria caracterizada por la desmielinización de los haces de nervios en el sistema nervioso central [10].

\section{Regulación de la respuesta inmune adaptativa de células $T$ por IFN tipo I}

Luego de la estimulación del complejo receptor de células T (TCR)/CD3 y el del receptor de co-estimulación $\mathrm{CD} 28$, las células $\mathrm{T} \mathrm{CD}^{+}$ vírgenes se diferencian en varios subconjuntos efectores tales como Th1, Th2, Th17, y subconjuntos reguladores (Treg y $\operatorname{Tr} 1$ ) bajo la influencia de citoquinas de polarización tales como IL-2, IFN $\gamma$, IL-4, IL-4, IL-13, IL-17, entre otras. Los IFN tipo I ejercen un efecto complejo sobre la diferenciación de células $\mathrm{T} \mathrm{CD} 4^{+}$. Los IFN tipo I activan STAT4 y por lo tanto deben promover el desarrollo de células Th1. Sin embargo, esto ha demostrado no ser suficiente para conducir un óptimo compromiso de células Th1 in vitro. Los IFN tipo I inhiben el desarrollo de células Th2 por la disminución de la expresión del factor de transcripción GATA3, y suprimen la diferenciación de células Th17 en ratones y seres humanos [11].

Por otro lado, Levings et al. (2001) reportaron que el IFNa e IL-10 puede inducir la diferenciación de células $\mathrm{T} \mathrm{CD}^{+}$vírgenes en células $\mathrm{T} \mathrm{CD}^{+}$reguladoras tipo 1 (células $\operatorname{Tr} 1$ ) que son Foxp3 3 y co-producen IL-10 e IFN $\gamma$. Este grupo también ha demostrado que la IL-10 es necesaria para la diferenciación de las células $\operatorname{Tr} 1$ por las células dendríticas inmaduras [12,13]. Asimismo, Corre et al. (2013) demostraron que el IFN $\alpha$ coopera con la estimulación TCR/CD3 en células $\mathrm{T} \mathrm{CD}^{+}$vírgenes, resultando en la potenciación de la secreción de IL-10. Este trabajo también mostró, a diferencia de Levings et al. (2001), que el IFN $\alpha$, y no IL-10, impulsa la diferenciación de células Tr1 que son IL- $10^{+}$, Foxp3-, IFN $\gamma^{-}$[14] (Figura 1).

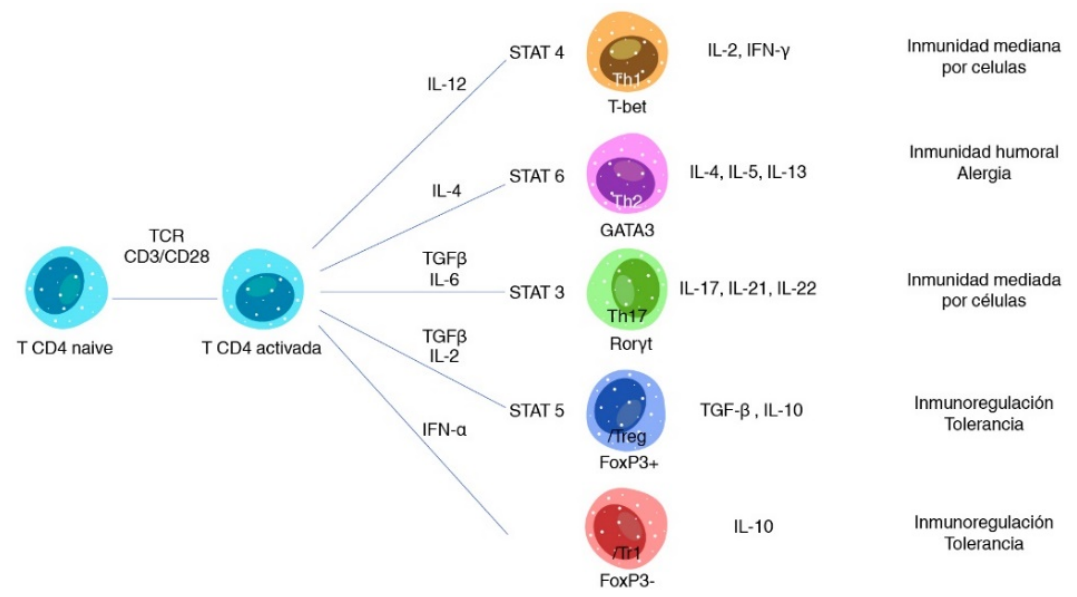

Figura 1. Principales vías de diferenciación de las células $\mathrm{T}$ CD4. Adaptado de O'Shea and Paul, 2010 [15]; Leung S. et al., 2010 [16]. 


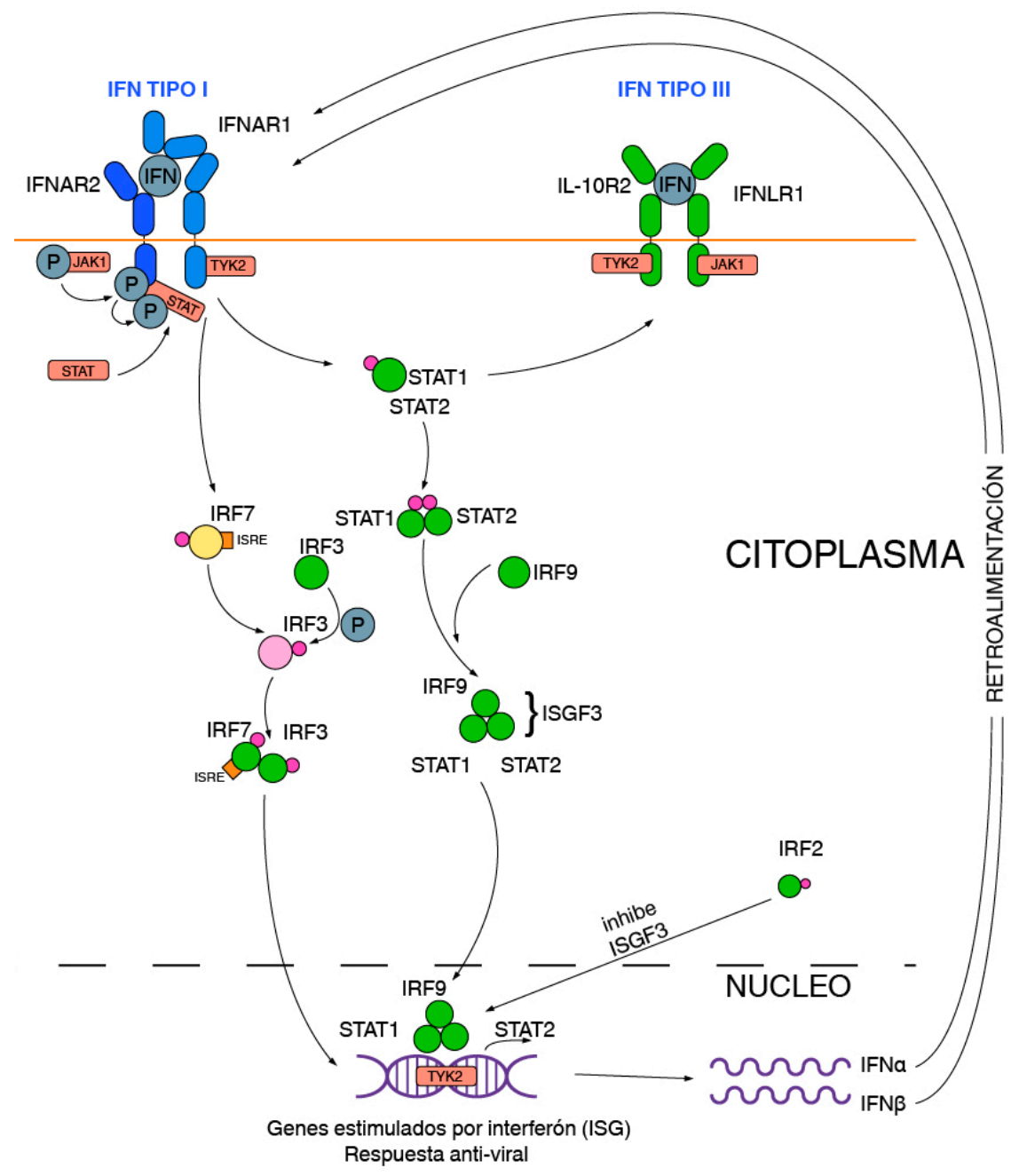

Figura 2. Cascada de señalización de los interferones tipo I y tipo III. Tomado y adaptado de Schneider et al., 2014 [40], y de R\&D Systems [41,42].

\section{LA FAMILIA DE INTERFERONES TIPO III}

Expresión, receptor y mecanismos de señalización

La familia de interferones tipo III (IFN $\lambda$ ) fue descrita por primera vez en el año 2003 incluyendo los subtipos IFN $\lambda 1$ (IL-29), IFN $\lambda 2$ (IL-28A), e IFN $\lambda 3$ (IL-28B) [17,18] y en el 2013 fue descrito el subtipo IFN $\lambda 4$ [19]. Los IFN tipo III son producidos por células nucleadas después de la infección viral [20].

Todos los IFN tipo III se unen a un receptor complejo heterodimérico, que se compone de dos subunidades, IL-28R $\lambda$ (IFN $\lambda$ R1) e IL-10R $\beta$ (IFN入R2). Este último es utilizado por otras citoquinas de la familia IL-10 (IL-10, IL-19, IL20, IL-22, IL-24 e IL-26). A diferencia de IL$10 \mathrm{R} \beta$, que se expresa de forma ubicua, la expresión de IL-28R $\lambda$ parece estar restringida a células epiteliales, hepatocitos, melanocitos $\mathrm{y}$ células neuronales [21-23].

Los IFN tipo III luego de unirse a su receptor heterodimérico provocan un cambio conformacional sobre los receptores IFN $\lambda \mathrm{R} 1 \mathrm{e}$ IFN $\lambda$ R2, que asocia Jak1 (Janus kinase 1) a IFN $\lambda$ R1 y Tyk2 (Tyrosine kinase 2) a IFN $\lambda$ R2. A pesar de los diferentes complejos de receptores, la vía de señalización de los IFN tipo III es similar a la de los IFN tipo I y conduce al reclutamiento y la fosforilación de diferentes STATs y a la expresión de ISGs a través de la formación del complejo ISGF3 [24] (Figura 2). La señalización a través de IFN $\lambda R$ también resulta en la fosforilación de tirosina de STAT3 y STAT5 [25]. Por otro lado, Witte et al. (2009) sugieren que las células inmunitarias de la sangre humana no son, o son débilmente, sensibles a los IFN $\lambda$ s [24], pero otros grupos proponen que los IFN $\lambda$ s tienen un efecto directo sobre los macrófagos, células 
dendríticas derivadas de monocitos, células dendríticas plasmacitoides y células T [26-32].

\section{Actividades terapéuticas biológicas y potenciales}

Los estudios de asociación del genoma completo (GWAS) han analizado la respuesta virológica sostenida (la ausencia de virus detectable al final del tratamiento con IFNa pegilado más ribavirina) en más de 1000 personas con infección crónica por el Virus de Hepatitis C (VHC). Los polimorfismos de nucleótido únicos (SNPs) en el gen IFNL3 (IL-28B) se asociaron con la eliminación espontánea del VHC. Estos SNPs se expresan de forma aleatoria según la etnia, pero se asociaron con una mayor protección en las personas de ascendencia africana en relación con ascendencia europea [33-36]. Asimismo, Hamming et al. (2014) demostraron que el IFN $\lambda 4$ recombinante posee una fuerte actividad antiviral contra la infección por VHC en líneas celulares de hepatocitos humanos, Huh7 y HepG2, en las vías respiratorias y las células epiteliales humanas después de la infección por coronavirus [37].

Si bien es cierto que el mecanismo antitumoral de los IFN tipo III no está claro, se puede promover la inhibición del crecimiento tumoral mediante la reducción de la vascularización en el microentorno del tumor [38]. En dos ensayos clínicos, ZymoGenetics Inc. investigó IFN $\lambda 1$ pegilado recombinante (peg-rIL-29), y los resultados de las fases $1 \mathrm{a}$ y $1 \mathrm{~b}$ indicaron que el peg-rIL-29 tiene un perfil de seguridad favorable cuando se administra con o sin ribavirina, que apoya la predicción de que IFN $\lambda$ puede ser utilizado como agente terapéutico [39].

\section{Regulación de la respuesta inmune adaptativa de células $T$ por IFN tipo III}

El papel de los IFN tipo III en la respuesta inmune es controversial. Algunos grupos afirman que los IFN tipo III no tienen ningún efecto sobre las células inmunitarias en sangre. Sin embargo, otros grupos sugieren que los IFN tipo III modulan la diferenciación de células $T$. Se ha propuesto que los IFN tipo III no actúan directamente sobre la mayoría de los tipos de leucocitos, linfocitos o monocitos debido a su incapacidad para inducir la señalización Jak/STAT [23]. Además, se han encontrado células inmunitarias en sangre que expresan una variante de empalme de IL-28R $\lambda$, pero su capacidad de respuesta a IFN tipo III no estaba clara [23]. Sin embargo, se ha demostrado que el mRNA de IFN $\lambda$ R1 es expresado por células dendríticas plasmocitoides y mieloides humanas, y linfocitos T y B [26-32].

El mRNA de IFN $\lambda \mathrm{R} 1$ es expresado también en las células $\mathrm{T} \mathrm{CD}^{+}{ }^{+}$vírgenes y de memoria, lo que apoya la idea de que el IFN $\lambda 1$ puede actuar directamente sobre estos subconjuntos de células. De manera similar a los IFN tipo I, el IFN $\lambda 1$ fue descrito como inhibidor de la diferenciación de las células Th2 por la regulación negativa de la expresión de GATA3 sin tener ningún efecto sobre la expresión de T-bet y, consecuentemente, sobre la polarización Th1 [30]. Asimismo, Misumi et al. (2014) publicaron recientemente efectos opuestos del IFN $\lambda$ en las respuestas de células $\mathrm{T}$ dirigidas contra el virus de la coriomeningitis linfocítica (LCMV), dependiendo del tipo de infección, aguda o crónica [32].

\section{CONCLUSIONES}

El papel que cumplen los IFN tipo I es bien conocido y definido, su participación en procesos tales como diferenciación, y proliferación; entre otros, es de vital importancia para la regulación de la respuesta inmune. Esta familia de interferones ha sido ampliamente estudiada y en la actualidad algunos de sus miembros se utilizan como agentes terapéuticos para diversas enfermedades. Por otro lado, su estudio ha permitido dilucidar los mecanismos de activación y transducción de señales después de la unión del interferón con su receptor, permitiendo de esta manera establecer mecanismos de regulación transcripcional y traduccional para comprender los mecanismos moleculares antes y después de una infección viral.

El papel de los IFN tipo III en la respuesta inmunitaria es, hasta la fecha, paradójico y contradictorio. Mientras que grupos de investigadores afirman que los IFN tipo III no tienen ningún efecto sobre las células inmunitarias, otro grupo de autores sugieren que los IFN tipo III modulan la diferenciación y las respuestas de las células T. Para una mejor comprensión del rol de los IFN tipo III es necesario fomentar la investigación sobre esta familia de interferones, y resultaría interesante identificar que poblaciones de células $\mathrm{T}$ pueden responder a IFN tipo III tras la estimulación del TCR, o para dilucidar los posibles mecanismos de presentación cruzada entre las células presentadoras de antígenos (APC) y las células T que pueden contribuir a la promoción de la secreción de IL-10 por estimulación de TCR/IFN$\lambda \mathrm{s}$. 


\section{AGRADECIMIENTOS}

Los autores agradecen el financiamiento del Vicerrectorado de Investigación y Posgrado de la Universidad Nacional Mayor de San Marcos (Código: B18100013)

\section{AUTOR DE CORRESPONDENCIA}

\section{MSc. Obert Marín Sánchez}

Instituto de Medicina Tropical "Daniel Alcides Carrión"

Facultad de Medicina

Universidad Nacional Mayor de San Marcos

E-mail: omarins@unmsm.edu.pe

\section{REFERENCIAS BIBLIOGRÁFICAS}

1. Aguilar J.L. Bases de la inmunología clínica. 1ed Edición. Lima. Sociedad Peruana de Inmunología; 2013. Capítulo 1, Conceptos básicos inmunológicos; p. 21-29.

2. Matzinger P. The danger model: a renewed sense of self. Science. 2002 Apr 12;296(5566):301-5.

3. Vinicius L. Ferreira, Helena H.L. Borba, Aline de F. Bonetti, Leticia P. Leonart and Roberto Pontarolo (March 13th 2018). Cytokines and Interferons: Types and Functions, Autoantibodies and Cytokines, Wahid Ali Khan, IntechOpen. Available from:

https://www.intechopen.com/books/autoanti bodies-and-cytokines/cytokines-andinterferons-types-and-functions

4. Isaacs A, Lindenmann J. Virus interference. I. The interferon. Proc Roy Soc, Ser.B, 1957, 147: 258-267.

5. Isaacs A, Lindenmann J. Valentine RC. Virus interference. II. Some properties of interferon. Proc Roy Soc, Ser. B, 1957, 147: 268-273.

6. Sato, M., T. Taniguchi, and N. Tanaka, The interferon system and interferon regulatory factor transcription factors -- studies from gene knockout mice. Cytokine \& Growth Factor Reviews, 2001. 12(2-3): p. 133-42.

7. Borden, E. C., Sen, G. C., Uze, G., Silverman, R. H., Ransohoff, R. M., Foster, G. R. and Stark, G. R., Interferons at age 50: past, current and future impact on biomedicine. Nat Rev Drug Discov 2007. 6: 975-990.Schneider, W. M., Chevillotte, M. D. and Rice, C. M., Interferon-stimulated genes: a complex web of host defenses. Annu Rev Immunol 2014. 32: 513-545.

8. Ivashkiv, L. B. and Donlin, L. T., Regulation of type I interferon responses. Nat Rev Immunol 2014. 14: 36-49.

9. Di Trolio, R., Simeone, E., Di Lorenzo, G., Grimaldi, A. M., Romano, A., Ayala, F., Caraco, C., Mozzillo, N. and Ascierto, P. A., Update on PEG-interferon alpha-2b as adjuvant therapy in melanoma. Anticancer Res 2012. 32: 3901-3909.

10. Fuertes, M. B., Woo, S. R., Burnett, B., Fu, Y. X. and Gajewski, T. F., Type I interferon response and innate immune sensing of cancer. Trends Immunol 2013. 34: 67-73.

11. Gonzalez-Navajas, J. M., Lee, J., David, M. and Raz, E., Immunomodulatory functions of type I interferons. Nat Rev Immunol 2012. 12: 125-135.

12. Levings, M. K., Sangregorio, R., Galbiati, F., Squadrone, S., de Waal Malefyt, R. and Roncarolo, M. G., IFN-alpha and IL-10 induce the differentiation of human type $1 \mathrm{~T}$ regulatory cells. J Immunol 2001. 166: 55305539.

13. Levings, M. K., Gregori, S., Tresoldi, E., Cazzaniga, S., Bonini, C. and Roncarolo, M. G., Differentiation of Tr1 cells by immature dendritic cells requires IL-10 but not CD25+CD4+ Tr cells. Blood 2005. 105: 1162-1169.

14. Corre, B., Perrier, J., El Khouri, M., Cerboni, S., Pellegrini, S. and Michel, F., Type I interferon potentiates $\mathrm{T}$-cell receptor mediated induction of IL-10-producing CD4(+) T cells. Eur J Immunol 2013. 43: 2730-2740.

15. O'Shea JJ, Paul WE. Mechanisms underlying lineage commitment and plasticity of helper CD4+ T cells. Science. 2010 Feb 26;327(5969):1098-102.

16. Leung S, Liu X, Fang L, Chen X, Guo T, Zhang J. The cytokine milieu in the interplay of pathogenic Th1/Th17 cells and regulatory $\mathrm{T}$ cells in autoimmune disease. Cell Mol Immunol. 2010 May;7(3):182-9.

17. Kotenko, S. V., Gallagher, G., Baurin, V. V., Lewis-Antes, A., Shen, M., Shah, N. K., Langer, J. A., Sheikh, F., Dickensheets, H. and Donnelly, R. P., IFN-lambdas mediate antiviral protection through a distinct class II cytokine receptor complex. Nat Immunol 2003. 4: 69-77.

18. Sheppard, P., Kindsvogel, W., Xu, W., Henderson, K., Schlutsmeyer, S., Whitmore, T. E., Kuestner, R., Garrigues, U., Birks, C., Roraback, J., Ostrander, C., Dong, D., Shin, 
J., Presnell, S., Fox, B., Haldeman, B., Cooper, E., Taft, D., Gilbert, T., Grant, F. J., Tackett, M., Krivan, W., McKnight, G., Clegg, C., Foster, D. and Klucher, K. M., IL28, IL-29 and their class II cytokine receptor IL-28R. Nat Immunol 2003. 4: 63-68.

19. Prokunina-Olsson, L., Muchmore, B., Tang, W., Pfeiffer, R. M., Park, H., Dickensheets, H., Hergott, D., Porter-Gill, P., Mumy, A., Kohaar, I., Chen, S., Brand, N., Tarway, M., Liu, L., Sheikh, F., Astemborski, J., Bonkovsky, H. L., Edlin, B. R., Howell, C. D., Morgan, T. R., Thomas, D. L., Rehermann, B., Donnelly, R. P. and O'Brien, T. R., A variant upstream of IFNL3 (IL28B) creating a new interferon gene IFNL4 is associated with impaired clearance of hepatitis C virus. Nat Genet 2013. 45: $164-$ 171.

20. O'Brien, T. R., Prokunina-Olsson, L. and Donnelly, R. P., IFN-lambda4: The Paradoxical New Member of the Interferon Lambda Family. J Interferon Cytokine Res 2014.

21. Pagliaccetti, N. E. and Robek, M. D., Interferon-lambda in $\mathrm{HCV}$ Infection and Therapy. Viruses 2010. 2: 1589-1602.

22. Dickensheets, H., Sheikh, F., Park, O., Gao, B. and Donnelly, R. P., Interferon-lambda (IFN-lambda) induces signal transduction and gene expression in human hepatocytes, but not in lymphocytes or monocytes. J Leukoc Biol 2013. 93: 377-385.

23. Witte, K., Gruetz, G., Volk, H. D., Looman, A. C., Asadullah, K., Sterry, W., Sabat, R. and Wolk, K., Despite IFN-lambda receptor expression, blood immune cells, but not keratinocytes or melanocytes, have an impaired response to type III interferons: implications for therapeutic applications of these cytokines. Genes Immun 2009. 10: 702-714.

24. Donnelly, R. P. and Kotenko, S. V., Interferon-lambda: a new addition to an old family. J Interferon Cytokine Res 2010. 30: 555-564.

25. Maher, S. G., Sheikh, F., Scarzello, A. J., Romero-Weaver, A. L., Baker, D. P., Donnelly, R. P. and Gamero, A. M., IFNalpha and IFNlambda differ in their antiproliferative effects and duration of JAK/STAT signaling activity. Cancer Biol Ther 2008. 7: 1109-1115.

26. Gallagher, G., Megjugorac, N. J., Yu, R. Y., Eskdale, J., Gallagher, G. E., Siegel, R. and Tollar, E., The lambda interferons: guardians of the immune-epithelial interface and the T- helper 2 response. J Interferon Cytokine Res 2010. 30: 603-615.

27. Yin, Z., Dai, J., Deng, J., Sheikh, F., Natalia, M., Shih, T., Lewis-Antes, A., Amrute, S. B., Garrigues, U., Doyle, S., Donnelly, R. P., Kotenko, S. V. and Fitzgerald-Bocarsly, P., Type III IFNs are produced by and stimulate human plasmacytoid dendritic cells. J Immunol 2012. 189: 2735-2745.

28. Jordan, W. J., Eskdale, J., Boniotto, M., Rodia, M., Kellner, D. and Gallagher, G., Modulation of the human cytokine response by interferon lambda-1 (IFN-lambda1/IL29). Genes Immun 2007. 8: 13-20.

29. Jordan, W. J., Eskdale, J., Srinivas, S., Pekarek, V., Kelner, D., Rodia, M. and Gallagher, G., Human interferon lambda-1 (IFN-lambda1/IL-29) modulates the Th1/Th2 response. Genes Immun 2007. 8: 254-261.

30. Dai, J., Megjugorac, N. J., Gallagher, G. E., $\mathrm{Yu}, \mathrm{R}$. Y. and Gallagher, G., IFN-lambda1 (IL-29) inhibits GATA3 expression and suppresses Th2 responses in human naive and memory T cells. Blood 2009. 113: 58295838 .

31. Megjugorac, N. J., Gallagher, G. E. and Gallagher, G., Modulation of human plasmacytoid DC function by IFN-lambda1 (IL-29). J Leukoc Biol 2009. 86: 1359-1363.

32. Misumi, I. and Whitmire, J. K., IFN-lambda Exerts Opposing Effects on $\mathrm{T}$ Cell Responses Depending on the Chronicity of the Virus Infection. J Immunol 2014. 192: 3596-3606.

33. Ge, D., Fellay, J., Thompson, A. J., Simon, J. S., Shianna, K. V., Urban, T. J., Heinzen, E. L., Qiu, P., Bertelsen, A. H., Muir, A. J., Sulkowski, M., McHutchison, J. G. and Goldstein, D. B., Genetic variation in IL28B predicts hepatitis $\mathrm{C}$ treatment-induced viral clearance. Nature 2009. 461: 399-401.

34. Suppiah, V., Moldovan, M., Ahlenstiel, G., Berg, T., Weltman, M., Abate, M. L., Bassendine, M., Spengler, U., Dore, G. J., Powell, E., Riordan, S., Sheridan, D., Smedile, A., Fragomeli, V., Muller, T., Bahlo, M., Stewart, G. J., Booth, D. R. and George, J., IL28B is associated with response to chronic hepatitis $\mathrm{C}$ interferonalpha and ribavirin therapy. Nat Genet 2009. 41: 1100-1104.

35. Tanaka, Y., Nishida, N., Sugiyama, M., Kurosaki, M., Matsuura, K., Sakamoto, N., Nakagawa, M., Korenaga, M., Hino, K., Hige, S., Ito, Y., Mita, E., Tanaka, E., Mochida, S., Murawaki, Y., Honda, M., 
Sakai, A., Hiasa, Y., Nishiguchi, S., Koike, A., Sakaida, I., Imamura, M., Ito, K., Yano, K., Masaki, N., Sugauchi, F., Izumi, N., Tokunaga, K. and Mizokami, M., Genomewide association of IL28B with response to pegylated interferon-alpha and ribavirin therapy for chronic hepatitis C. Nat Genet 2009. 41: 1105-1109.

36. Thomas, D. L., Thio, C. L., Martin, M. P., Qi, Y., Ge, D., O'Huigin, C., Kidd, J., Kidd, K., Khakoo, S. I., Alexander, G., Goedert, J. J., Kirk, G. D., Donfield, S. M., Rosen, H. R., Tobler, L. H., Busch, M. P., McHutchison, J. G., Goldstein, D. B. and Carrington, M., Genetic variation in IL28B and spontaneous clearance of hepatitis C virus. Nature 2009. 461: 798-801.

37. Hamming, O. J., Terczynska-Dyla, E., Vieyres, G., Dijkman, R., Jorgensen, S. E., Akhtar, H., Siupka, P., Pietschmann, T., Thiel, V. and Hartmann, R., Interferon lambda 4 signals via the IFNlambda receptor to regulate antiviral activity against $\mathrm{HCV}$ and coronaviruses. EMBO J 2013. 32: 30553065.

38. Lasfar, A., Abushahba, W., Balan, M. and Cohen-Solal, K. A., Interferon lambda: a new sword in cancer immunotherapy. Clin Dev Immunol 2011. 2011: 349575.

39. Donnelly, R. P., Dickensheets, H. and O'Brien, T. R., Interferon-lambda and therapy for chronic hepatitis $\mathrm{C}$ virus infection. Trends Immunol 2011. 32: 443450.

40. Schneider WM, Chevillotte MD, Rice CM. Interferon-stimulated genes: a complex web of host defenses. Annu Rev Immunol. 2014;32:513-45.

41. RnDSystems. Type I Interferon Signaling Pathways [Internet]. Minnesota USA: RnDSystems; 2019 [revisado 20 de mayo de 2019]. Disponible desde: https://www.rndsystems.com/pathways/type -i-interferon-signaling-pathways.

42. RnDSystems. Type III Interferon Signaling Pathways [Internet]. Minnesota USA: RnDSystems; 2019 [revisado 20 de mayo de 2019]. Disponible desde: https://www.rndsystems.com/pathways/type -i-interferon-signaling-pathways. 